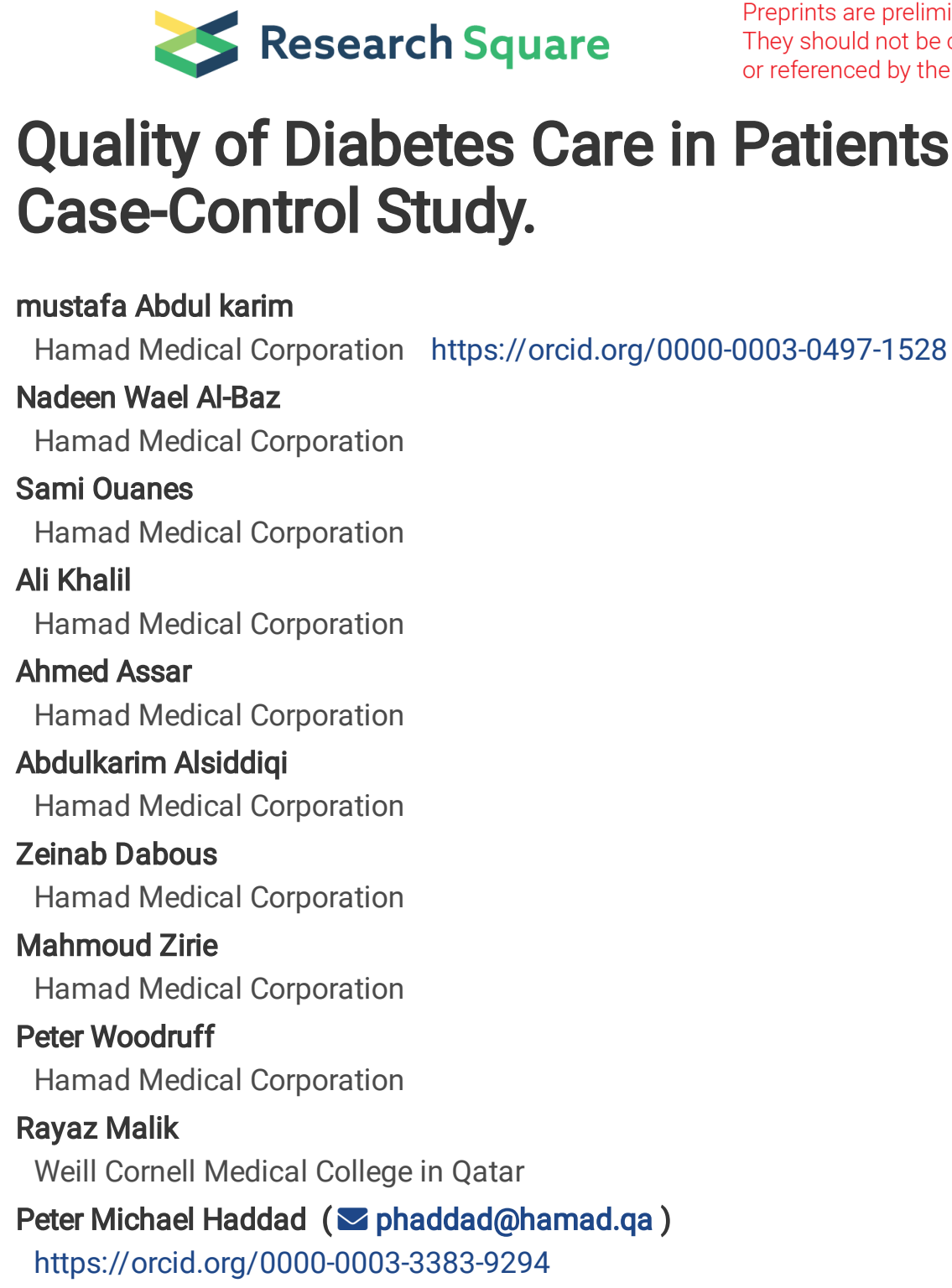

mustafa Abdul karim

Hamad Medical Corporation https://orcid.org/0000-0003-0497-1528

\section{Nadeen Wael Al-Baz}

Hamad Medical Corporation

\section{Sami Ouanes}

Hamad Medical Corporation

Ali Khalil

Hamad Medical Corporation

\section{Ahmed Assar}

Hamad Medical Corporation

Abdulkarim Alsiddiqi

Hamad Medical Corporation

\section{Zeinab Dabous}

Hamad Medical Corporation

Mahmoud Zirie

Hamad Medical Corporation

Peter Woodruff

Hamad Medical Corporation

\section{Rayaz Malik}

Weill Cornell Medical College in Qatar

Peter Michael Haddad ( $\sim$ phaddad@hamad.qa )

https://orcid.org/0000-0003-3383-9294

\title{
Quality of Diabetes Care in Patients with Schizophrenia: A Case-Control Study.
}

\section{Research article}

Keywords: Schizophrenia, Diabetes Mellitus, Diabetes Care

Posted Date: June 25th, 2020

DOI: https://doi.org/10.21203/rs.3.rs-27561/v1

License: (c) (i) This work is licensed under a Creative Commons Attribution 4.0 International License. Read Full License

Version of Record: A version of this preprint was published on March 12th, 2021. See the published version at https://doi.org/10.1186/s12888-021-03121-5. 


\section{Abstract}

\section{Background}

Patients with schizophrenia are at least twice as likely to develop diabetes mellitus compared to the general population. This is of significance in Qatar given the high prevalence of obesity and diabetes. Furthermore, the lifespan of people with schizophrenia and diabetes is shortened by approximately 15 years due to long-term microvascular and macrovascular complications. High quality diabetes care can significantly reduce morbidity and mortality. We assessed the level of diabetes care delivered to patients with schizophrenia and diabetes compared to those with diabetes alone.

\section{Methods}

We performed a retrospective chart review of patients with diabetes mellitus with $(n=73)$ and without $(n=73)$ schizophrenia. Demographic information and electronic medical records were reviewed for 6-month and 1-year American Diabetic Association standards of diabetes care. Optimal diabetes care was defined as having completed glycated hemoglobin (HbA1c), lipid profile and retinal examination within 12 months.

\section{Results}

Optimal diabetes care was significantly lower in patients with schizophrenia and diabetes compared to diabetes alone [26.0\% ( $n=19 / 73)$ vs $52.1 \%(n=38 / 73), p=0.002$ ]. Patients with diabetes and schizophrenia were also significantly less likely to have had body mass index recorded within six months $(p=0.008)$ and HbA1c $(p=0.006)$, lipid profile $(p=0.015)$, estimated glomerular filtration rate (eGFR) ( $p=0.001)$ and order for retinal screening $(p=0.004)$ over 12 months. After adjusting for multiple comparisons, only assessment of eGFR $(p=0.01)$ and order for retinal screening $(p=0.04)$ remained significant.

\section{Conclusion}

Patients with schizophrenia and diabetes in Qatar receive sub-optimal diabetes care compared to those with diabetes alone.

\section{Background}

Diabetes Mellitus (DM) has an estimated global prevalence of $8.5 \%$ in the adult population (1). Qatar, Kuwait, and Saudi Arabia in the Middle East and North Africa Region (MENA) are three of the top 10 countries with the highest diabetes prevalence worldwide (2). In Qatar, 70.1\% of Qatari nationals are clinically overweight (Body Mass Index (BMI) $\geq 25 \mathrm{~kg} / \mathrm{m}^{2}$ ), and $41.4 \%$ obese $\left(\mathrm{BMI} \geq 30 \mathrm{~kg} / \mathrm{m}^{2}\right)$ (3). The prevalence of diabetes in people with schizophrenia is estimated to be 2 to 3 times higher compared to the general population (4), with over four-fold increased odds of comorbid diabetes in patients with non-affective psychosis and a family history of type II DM (5). Recently, a retrospective cohort study from Scotland has shown greater diabetes incidence in women compared to men with schizophrenia (RR 2.40 [95\% Confidence Interval (Cl) $2.01,2.85]$ and $1.63[1.38,1.94])$, respectively) (6). The high prevalence of diabetes in people with schizophrenia generally reflects multiple factors including a more sedentary lifestyle, higher prevalence of obesity, poor diet, metabolic side effects of antipsychotic medication and possibly intrinsic factors including genetic predisposition and inflammation (7). Nielsen et al showed that second generation antipsychotics were associated with an increased risk of diabetes (8). However, a study in Qatar did not find a higher prevalence of metabolic syndrome in patients receiving antipsychotics (9). Dysglycemia is also associated with the severity of schizophrenia, particularly negative symptoms and cognitive impairment (10). All-cause mortality for people with schizophrenia is significantly increased, with a recent longitudinal study in the United States showing an all-cause standardized mortality ratio of 3.7 (95\% Cl, 3.7-3.7) (11). The lifespan of patients with schizophrenia is shortened by approximately 15 years with the largest single cause of death being cardiovascular disease (12). Provision of high-quality diabetes care, particularly the management of cardiovascular risk factors, could reduce this elevated morbidity and mortality and healthcare costs for providers.

Page $2 / 10$ 
Delivering optimal diabetes care in patients with schizophrenia can be challenging as patient, provider, treatment and system-level factors may act as barriers to following evidence-based guidelines (13). Several studies have reported that patients with DM and serious mental illness (SMI) are less likely to receive optimal diabetes care (13-16). In Canada, Kurdyak et al (2017) showed that schizophrenia was associated with a reduced likelihood of optimal diabetes care (HbA1c, lipid profile and retinal exam) over the preceding 2 years [adjusted odds ratio (OR) (95\% Cl): $0.64(0.61-0.67)$ ] and an increased likelihood of diabetes-related emergency department (ED) visits (adjusted OR (95\% Cl): 1.34 (1.28-1.41)) and hospitalization (adjusted OR (95\% Cl): $1.36(1.28-1.43))(13)$. These results confirm those of an earlier study showing an increased rate of diabetes-related emergency department visits in people with schizophrenia (Hazard Ratio $=1.74,95 \% \mathrm{Cl}$ (1.42-2.12)) (17). Indeed, the non-treatment rates for diabetes in the Clinical Antipsychotic Trials of Intervention Effectiveness (CATIE) study in patients with schizophrenia was $45.3 \%$ (18). However, a study by Whyte et al found the quality of diabetes care in the United Kingdom comparable between patients with schizophrenia or bipolar disorder with comorbid diabetes and those with diabetes alone (19). Engagement with mental health services and adherence to antipsychotic treatment is associated with significant reduction in diabetes related hospitalization (20). An association has also been found between more frequent outpatient psychiatry $(\mathrm{OR}=1.28,95 \% \mathrm{Cl}=1.20-1.37)$ and primary care $(\mathrm{OR}=2.10$, $95 \% \mathrm{Cl}=1.85-2.39)$ visits and optimal diabetes testing (21).

The quality of diabetes care received by people with schizophrenia in Qatar has not been investigated previously. This is of relevance in Qatar given the high prevalence of obesity and diabetes. Our aim was to determine the quality of diabetes care in patients with schizophrenia and DM compared to patients with diabetes alone.

\section{Methods}

We identified two cohorts of patients on the CERNER Electronic Medical Records (EMRs) system in outpatient clinics in Hamad Medical Corporation (HMC), Doha, Qatar: those with DM and schizophrenia (study group) and those with DM and no serious psychiatric illness (control group). Cohorts were limited to subjects 18 years of age and older, both genders, all nationalities and with type 2 diabetes. Diagnoses of both DM and schizophrenia were based on documented clinical diagnosis on EMRs and subjects were matched for the service followed for diabetes care. Standards of diabetes care were retrospectively recorded for the year 2018, and patients were only included if they were diagnosed with both DM and schizophrenia prior to 2018. Patients were assigned subject numbers and selected using a random number generator. Based on recommendations by the American Diabetes Association (ADA) (22), we identified the completion of the following investigations/measurements/ examinations as measures of optimal diabetes care: $\mathrm{HbA1c}$, BMI and blood pressure over six months (July through December 2018) and HbA1c, BMI, blood pressure, lipid profile, retinal examination, foot examination, serum creatinine and eGFR over 12 months (January through December of 2018). In addition, we recorded the total number of medical and psychiatric admissions over 12 months and referrals to the dietician and diabetes educators.

\section{Sample Size Calculation}

A previous study showed that the rate of $\mathrm{HbA1c}$ testing in patients with schizophrenia and DM was significantly lower compared to patients with diabetes alone (48\% vs $71 \%, p=.0001)(23)$. Using the same proportions, with an alpha $=0.05$, power $=0.9$, and sample size distribution ratio of $1: 1$, the calculated sample size in each group was 73 , with a total sample size of $146(24)$.

\section{Statistical Analysis}

Statistical analysis was conducted using the Statistical Package for the Social Sciences (IBM-SPSS, version 23.0, IBM Corp, Armonk, NY, USA). For categorical variables, we calculated the frequency. For continuous variables, we calculated the mean and standard deviation (SD). The differences between the study and control groups were analyzed using Pearson's chisquared test for categorical variables (and in case of non-validity, the Fishers' exact test), and t-test for continuous 
variables. Optimal diabetes care was defined as having completed all three of $\mathrm{HbA} 1 \mathrm{c}$, lipid profile, and eye examination within 12 months, adapted from a previous study by Kurdyak et al (13). We assessed all the key ADA measures of diabetes care. For multiple comparisons, p values were adjusted using the Holm Bonferroni method.

\section{Results}

\section{Sociodemographic and clinical characteristics of the groups}

The study assessed participants with schizophrenia and diabetes $(n=73)$ versus those with diabetes only $(n=73)$.

Participants with diabetes and schizophrenia were significantly younger compared to the control group (45.1 \pm 13.0 vs 57.9 $\pm 11.1 ; p<0.001)$. There was no significant difference for gender or nationality between groups (Table 1 ). The number of psychiatric and medical admissions combined did not differ significantly between groups.

\section{Standards of optimal diabetes care}

Five standards were significantly less likely to be met in patients with diabetes and schizophrenia compared to diabetes alone: BMI recorded within six months $(p=0.008)$, and HbA1c $(p=0.006)$, lipid profile $(p=0.015)$, eGFR $(p=0.001)$ and order for retinal screening $(p=0.004)$ over 12 months. However, after adjusting for multiple comparisons, only assessment of eGFR ( $p=0.01)$ and order for retinal screening $(p=0.04)$ remained significant (Table 2$)$. Using the three-item definition of optimal diabetes care ( $\mathrm{HbA1c}$, lipid profile and eye examination over 12 months), patients with diabetes and schizophrenia were less likely to receive optimal diabetes care compared to those with diabetes alone $[26.0 \%(n=19 / 73)$ vs $52.1 \%(n=$ 38/73), $p=0.002]$.

Table 1

Sociodemographic and clinical characteristics of patients with diabetes vs patients with diabetes and schizophrenia.

\begin{tabular}{|llll|}
\hline & Diabetes & $\begin{array}{l}\text { Diabetes } \\
\text { + Schizophrenia }\end{array}$ & \\
\hline N & & 73 & \\
\hline Age, years & 73 & $73.1 \pm 13.0$ & 0.001 \\
\hline Gender, \% male & $57.9 \pm 11.1$ & 45.1 & 0.500 \\
\hline Nationality & 57.5 & 58.9 & 0.063 \\
Qatari, \% & 46.6 & 60.3 & \\
Non-Qatari Arab, \% & 24.7 & 19.2 & \\
South Asian, \% & 23.3 & 9.6 & \\
\hline Other, \% & 5.4 & 10.9 & 0.690 \\
\hline Last BMI, Kg/m ${ }^{2}$ & & & 0.055 \\
\hline Last HbA1c, \% & $32.6 \pm 6.1$ & $32.1 \pm 7.5$ & 0.286 \\
\hline Number of admissions over the last year & 11 & $7.4 \pm 2.3$ & \\
\hline
\end{tabular}


Data expressed as Mean \pm Standard Deviation; BMI: Body Mass Index

Table 2. Standards of optimal diabetes care and monitoring in patients with diabetes vs patients with diabetes and schizophrenia.

\begin{tabular}{|c|c|c|c|c|}
\hline & Diabetes & Diabetes + Schizophrenia & $p$ & Adjusted $p$ \\
\hline $\begin{array}{l}\text { BMI recorded in the last six } \\
\text { months, \% }\end{array}$ & 72.6 & 52.1 & 0.008 & 0.064 \\
\hline $\begin{array}{l}\text { BP recorded in the last six } \\
\text { months, \% }\end{array}$ & 95.9 & 94.5 & 0.500 & 1.000 \\
\hline $\begin{array}{l}\text { HbA1c obtained in the last } \\
\text { six months, \% }\end{array}$ & 72.6 & 63.0 & 0.144 & 0.567 \\
\hline $\begin{array}{l}\text { HbA1c obtained in the last } \\
12 \text { months, \% }\end{array}$ & 84.9 & 65.8 & 0.006 & 0.054 \\
\hline $\begin{array}{l}\text { Lipid panel obtained in the } \\
\text { last } 12 \text { months, \% }\end{array}$ & 84.9 & 68.5 & 0.015 & 0.105 \\
\hline $\begin{array}{l}\text { eGFR obtained in the last } \\
12 \text { months, \% }\end{array}$ & 89.0 & 67.1 & 0.001 & 0.011 \\
\hline $\begin{array}{l}\text { Retinal screen ordered } \\
\text { within in } 12 \text { months, \% }\end{array}$ & 57.5 & 34.2 & 0.004 & 0.040 \\
\hline $\begin{array}{l}\text { Retinal screen completed } \\
\text { within } 12 \text { months, \% }\end{array}$ & 8.2 & 1.4 & 0.527 & 1.000 \\
\hline $\begin{array}{l}\text { Podiatry screen ordered } \\
\text { within } 12 \text { months, } \%\end{array}$ & 17.8 & 17.8 & 0.585 & 1.000 \\
\hline $\begin{array}{l}\text { Referral to diabetes } \\
\text { educator within } 12 \text { months, } \\
\%\end{array}$ & 17.8 & 9.6 & 0.114 & 0.576 \\
\hline \multirow{2}{*}{$\begin{array}{l}\text { Referred to dietitian } \\
\text { within12 months, \% }\end{array}$} & 30.1 & 17.8 & 0.060 & 0.360 \\
\hline & \multicolumn{4}{|c|}{$\begin{array}{l}\text { BMI: Body Mass Index; BP: Blood pressure; eGFR: estimated glomerular filtration rate; } \\
\text { p values were adjusted using the Holm Bonferroni method. }\end{array}$} \\
\hline
\end{tabular}

\section{Discussion}

In this study patients with diabetes and schizophrenia were half as likely to receive optimal diabetes care compared to those with diabetes alone using the three-item definition ( $\mathrm{HbA} 1 \mathrm{c}$, lipid profile and retinal examination over 12 months). A Canadian study using the same definition over two years reported very similar findings (14). More recently, a nationwide Danish study found that patients with schizophrenia were less likely to receive high quality diabetes care (defined as fulfilling $80 \%$ of recommended measures) (14).

Suboptimal diabetes care in our study group may be attributed to a lack of integrated physical and mental health services and difficulty sharing information and expertise amongst health care specialties (25). Negative symptoms in schizophrenia including lack of motivation, goal-directed activity, and disorganization (26) might affect patient's adherence with treatment and clinic appointments, and are associated with poorer mental health outcomes. Schizophrenia is also frequently comorbid with depression and substance misuse $(28,29)$, which can further hinder engagement with diabetes care. Socioeconomic status is unlikely to affect the quality of care in Qatar, as health care services are mostly free of charge for citizens and provided with minimal charge for residents of the country. Stigma against mental illness may affect quality of 
care and act as a barrier to health care access (30). In Qatar, $40.6 \%$ of surveyed individuals perceive patients with psychiatric disorders as mentally challenged and $48.3 \%$ believe mental illness is a punishment from God (31).

Patients with diabetes alone were significantly older compared to those with both diabetes and schizophrenia, which could reflect the earlier onset of type 2 diabetes due to lifestyle and medications used for schizophrenia (12). However, the level of obesity (BMI) and glycemic control ( $\mathrm{HbA} 1 \mathrm{c})$ was comparable between the two groups. A recent study in Qatar also found no difference in the prevalence of metabolic syndrome in patients receiving antipsychotics (9). The high prevalence of diabetes and obesity in the Qatar population could explain a lack of further effect of antipsychotics or schizophrenia on these outcomes $(2,3)$.

We propose several strategies to reduce the inequalities reported. Educational awareness programs should be instated and encouraged to address mental health stigma and negative stereotypes. Further work is required to increase awareness amongst HCPs regarding the increased morbidity and mortality in patients with schizophrenia. Communication between different services providing health care for patients with schizophrenia is essential to ensuring access to health care services and optimizing management of medical comorbidities. Education to prevent or limit obesity and diabetes needs to be promoted among patients with severe mental illness to help decrease the prevalence of diabetes and ensure that those diagnosed with DM receive high quality care. These recommendations are in line with the recently published blueprint for protecting physical health in people with mental illness (32).

\section{Strengths And Limitations}

This population-based study included randomly assigned patients from both genders and all nationalities followed in outpatient clinics. Data to identify and control for the duration of DM and schizophrenia in our cohorts was limited as the EMRs system was started in 2015. Additionally, important demographic information such as smoking, marital and socioeconomic status were missing or inconsistently documented. Nevertheless, lab results, orders and documentation pertaining to diabetes care were easily extractible, and the criteria for optimal diabetes care were clearly defined. As this is a case-control study, the incidence and relative risk of suboptimal diabetes care in patients with schizophrenia could not be calculated.

\section{Conclusion}

This study found that patients with schizophrenia and DM in Qatar are less likely to receive optimal diabetes care compared to patients with diabetes alone, particularly in relation to the microvascular complications with a decreased frequency of eGFR completion and order for retinal screening. These data encourage further population cohort studies to assess adherence with treatment and the burden of diabetes-related medical comorbidities and complications in patients with schizophrenia.

\section{Abbreviations}

ADA

American Diabetes Association

BMI

Body-Mass Index

CATIE

Clinical Antipsychotic Trials of Intervention Effectiveness

CVD

Cardiovascular Disease

$\mathrm{Cl}$ 
Confidence Interval

DM

Diabetes Mellitus

ED

Emergency Department

eGFR

estimated Glomerular Filtration Rate

EMRs

Electronic Medical Records

$\mathrm{HbA1c}$

Glycosylated Hemoglobin

HCPs

Health Care Professionals

HMC

Hamad Medical Corporation

MENA

Middle East and North Africa

OR

Odds Ratio

SMI

Serious Mental IIIness

\section{Declarations}

\section{Ethics approval and consent to participate}

The study proposal was approved by the Institutional Review Board (IRB) and Medical Research Center (MRC) at Hamad Medical Corporation (HMC).

Proposal ID: MRC-01-19-051

The study was a retrospective case note review and patient consent was not required (this decision was approved by the IRB).

Consent for publication: not applicable

Availability of data and materials: Supplementary material is available on request.

Competing Interests: In the last 3 years, Professor Peter Michael Haddad has received honoraria for lecturing and consultancy from the manufacturers of several antipsychotic drugs. The other authors declare that they have no competing interests.

Funding: the project received no funding from any governmental or private institution

\section{Author's Contributions:}

MAK: Helped with conducting literature review, data collection and writing methods and discussion. Helped obtain patient list for the schizophrenia and diabetes group.

NA-B: Helped with conducting literature review, study design, data collection and writing methods. Helped in obtaining patient lists for the diabetes only group and liaison with the endocrinology department.

Page $7 / 10$ 
SO: Helped with study design, statistical analysis and writing methods and results section.

AK: Helped with study design, data collection and writing the abstract.

AA: Helped with study design, data collection, and writing the methods section.

AS: Helped with study design, data collection, and writing the results section.

ZD: Helped with study design, establishing recommended measures of diabetes care, data collection set, and writing the methods section.

MZ: Helped with study design, establishing recommended measures of diabetes care, data collection set and editing the paper.

PW: Helped with study design, obtaining IRB and MRC approval, and editing the paper.

RM: Helped study design, establishing recommended measures of diabetes care, data collection and writing the methods section.

PMH: Helped with conducting the literature review, study design, obtaining list of patients and drafting the paper.

All authors read and approved the final manuscript.

Acknowledgments: not applicable

\section{References}

1. Sarwar N, Gao P, Kondapally Seshasai SR, Gobin R, Kaptoge S, Di Angelantonio E, et al. Diabetes mellitus, fasting blood glucose concentration, and risk of vascular disease: A collaborative meta-analysis of 102 prospective studies. Lancet. 2010;375(9733):2215-22.

2. Aguiree F, Brown A, Cho NH, Dahlquist G, Dodd S, Dunning T, Hirst M, Hwang C, Magliano D, Patterson C, Scott C, Shaw J, Soltesz G, Usher-Smith J WD. International Diabetes Federation. IDF Diabetes Atlas, 6th edn. [Internet]. Brussels, Belgium: International Diabetes Federation. 2013. Available from: http://www.idf.org/diabetesatlas

3. Healthy Lifestyle - Ministry of Public Health [Internet]. [cited 2019 Dec 14]. Available from: https://phs.moph.gov.qa/data/healthy-lifestyle/

4. De Hert M, Correll CU, Bobes J, Cetkovich-Bakmas M, Cohen DAN, Asai I, et al. Physical illness in patients with severe mental disorders. I. Prevalence, impact of medications and disparities in health care. Vol. 10, World Psychiatry. Blackwell Publishing Ltd; 2011. p. 52-77.

5. Chung J, Miller BJ. Meta-analysis of comorbid diabetes and family history of diabetes in non-affective psychosis. Schizophrenia Research. Elsevier B.V.; 2019.

6. Jackson CA, Fleetwood K, Kerssens J, Smith DJ, Mercer S, Wild SH. Incidence of type 2 diabetes in people with a history of hospitalization for major mental illness in Scotland, 2001-2015: A retrospective cohort study. In: Diabetes Care. American Diabetes Association Inc.; 2019. p. 1879-85.

7. Hoffman R. The Complex Inter-Relationship Between Diabetes and Schizophrenia. Curr Diabetes Rev. 2017;13(3):52832.

8. Nielsen J, Skadhede S, Correll CU. Antipsychotics associated with the development of type 2 diabetes in antipsychoticnaïve schizophrenia patients. Neuropsychopharmacology. 2010 Aug;35(9):1997-2004.

9. Hammoudeh S, Ghuloum S, Mahfoud Z, Yehya A, Abdulhakam A, Al-Mujalli A, et al. The prevalence of metabolic syndrome in patients receiving antipsychotics in Qatar: A cross sectional comparative study. BMC Psychiatry. 2018 
Mar 27;18(1).

10. Perry BI, Salimkumar D, Green D, Meakin A, Gibson A, Mahajan D, et al. Associated illness severity in schizophrenia and diabetes mellitus: A systematic review. Vol. 256, Psychiatry Research. Elsevier Ireland Ltd; 2017. p. 102-10.

11. Olfson M, Gerhard T, Huang C, Crystal S, Stroup TS. Premature mortality among adults with schizophrenia in the United States. JAMA Psychiatry. 2015 Dec 1;72(12):1172-81.

12. Hjorthøj C, Stürup AE, McGrath JJ, Nordentoft M. Years of potential life lost and life expectancy in schizophrenia: a systematic review and meta-analysis. The Lancet Psychiatry. 2017 Apr 1;4(4):295-301.

13. Kurdyak P, Vigod S, Duchen R, Jacob B, Stukel T, Kiran T. Diabetes quality of care and outcomes: Comparison of individuals with and without schizophrenia. Gen Hosp Psychiatry. 2017 May 1;46:7-13.

14. Jørgensen M, Mainz J, Carinci F, Thomsen RW, Johnsen SP. Quality and predictors of diabetes care among patients With schizophrenia: A Danish nationwide study. In: Psychiatric Services. American Psychiatric Association; 2018. p. 179-85.

15. Druss BG, Zhao L, Cummings JR, Shim RS, Rust GS, Marcus SC. Mental comorbidity and quality of diabetes care under medicaid: A 50-state analysis. Med Care. 2012 May;50(5):428-33.

16. Frayne SM, Halanych JH, Miller DR, Wang F, Lin H, Pogach L, et al. Disparities in diabetes care: Impact of mental illness. Arch Intern Med. 2005 Dec 12;165(22):2631-8.

17. Becker T, Hux J. Risk of acute complications of diabetes among people with schizophrenia in Ontario, Canada. Diabetes Care. 2011 Feb;34(2):398-402.

18. Nasrallah HA, Meyer JM, Goff DC, McEvoy JP, Davis SM, Stroup TS, et al. Low rates of treatment for hypertension, dyslipidemia and diabetes in schizophrenia: Data from the CATIE schizophrenia trial sample at baseline. Schizophr Res. 2006 Sep;86(1-3):15-22.

19. Whyte S, Penny C, Phelan M, Hippisley-Cox J, Majeed A. Quality of diabetes care in patients with schizophrenia and bipolar disorder: cross-sectional study. Diabet Med. 2007;24:1442-8.

20. Eggle K, Cogan L, Leckman-westin E, Finnerty M. Antipsychotic medication adherence and diabetes-related hospitalizations among medicaid recipients with diabetes and schizophrenia. Psychiatr Serv. 2019;advance(advance):1-7.

21. Hsu JH, Calzavara A, Vigod S, Stukel TA, Kiran T, Kurdyak P. Factors Associated With Diabetes Care Quality Among Patients With Schizophrenia in Ontario, Canada. Psychiatr Serv [Internet]. 2019 Nov 20 [cited 2020 Jan

20];appi.ps.2019000. Available from: https://psychiatryonline.org/doi/10.1176/appi.ps.201900009

22. Standards of Medical Care in Diabetes. 2018;41, Supple:1-159. Available from: https://care.diabetesjournals.org/content/diacare/suppl/2017/12/08/41.Supplement_1.DC1/DC_41_S1_Combined.pdf

23. O'Connor P. Impact of Schizophrenia Diagnosis on Diabetes Care in Adults | American Diabetes Association [Internet]. Abstract Number 2807-PO. 2007 [cited 2019 Nov 13]. Available from: https://professional.diabetes.org/abstract/impact-schizophrenia-diagnosis-diabetes-care-adults

24. Jennifer K, Whittemore A, Evans A, Thompson D. Methods in Observational Epidemiology. second. 1996. Table 12-15.

25. Druss BG. Improving medical care for persons with serious mental illness: Challenges and solutions. Vol. 68, Journal of Clinical Psychiatry. 2007. p. 40-4.

26. Sarkar S. Conceptualization and treatment of negative symptoms in schizophrenia. World J Psychiatry. 2015;5(4):352.

27. Patel R, Jayatilleke N, Broadbent M, Chang CK, Foskett N, Gorrell G, et al. Negative symptoms in schizophrenia: A study in a large clinical sample of patients using a novel automated method. BMJ Open. 2015;5(9).

28. Buckley PF, Miller BJ, Lehrer DS, Castle DJ. Psychiatric comorbidities and schizophrenia. Schizophr Bull [Internet]. 2009 Mar [cited 2020 Jan 21];35(2):383-402. Available from: http://www.ncbi.nlm.nih.gov/pubmed/19011234

29. Hartz SM, Pato CN, Medeiros H, Cavazos-Rehg P, Sobell JL, Knowles JA, et al. Comorbidity of severe psychotic disorders with measures of substance use. JAMA psychiatry [Internet]. 2014 Mar [cited 2020 Jan 21];71(3):248-54.

Page 9/10 
Available from: http://www.ncbi.nlm.nih.gov/pubmed/24382686

30. Knaak S, Mantler E, Szeto A. Mental illness-related stigma in healthcare: Barriers to access and care and evidencebased solutions. Vol. 30, Healthcare Management Forum. SAGE Publications Inc.; 2017. p. 111-6.

31. Ghuloum S, Bener A, Burgut FT. Epidemiological Survey of Knowledge, Attitudes, and Health Literacy Concerning Mental Illness in a National Community Sample: A Global Burden. J Prim Care Community Health. 2010;1(2):111-8.

32. Firth J, Siddiqi N, Koyanagi A, Siskind D, Rosenbaum S, Galletly C, et al. The Lancet Psychiatry Commission: a blueprint for protecting physical health in people with mental illness. Vol. 6, The Lancet Psychiatry. Elsevier Ltd; 2019. p. 675712. 